\title{
BнA. ТУТЕЛЬЯН,
}

д-р мед. наук, академик РАН, профессор, ФГБУН «ФИЦ питания и биотехнологии», г. Москва, Россия; Первый Московский государственный медицинский университет им. И.М. Сеченова, г. Москва, Россия, e-mail: tutelyan@ion.ru

\section{ЗДОРОВОЕ ПИТАНИЕ АЛЯ ОБЩЕСТВЕННОГО ЗДОРОВЬЯ}

УДК: 614.2

DOI: 10.21045/2782-1676-2021-1-1-56-64

Тутельян В.А. Здоровое питание для общественного здоровья (ФГБУН «ФИЦ питания, биотехнологии и безопасности пищи», г. Москва, Россия; Первый Московский государственный медицинский университет имени И.М. Сеченова, г. Москва, Россия)

Аннотация: Рассмотрено понятие здорового питания, как ключевого фактора, формирующего здоровье человека во все периоды жизни, а также его основополагающие принципы, базирующиеся на основных законах о питании. Отдельное внимание уделено вопросам безопасности пищи, обеспечению физиологических потребностей в энергии, пищевых и биологически активных веществах, важности разнообразия и сбалансированности рациона. Отражены основные нарушения структуры питания населения Российской Федерации и предложены эффективные инструменты для ее улучшения, профилактики алиментарнозависимых неинфекционных заболеваний и здоровьесбережения нации.

Ключевые слова: общественное здоровье, здоровое питание, минорные компоненты пищи, метаболизм, биологически активные вещества, безопасность пищи.

Для цитирования: Тутельян В.А. Здоровое питание для общественного здоровья // Общественное здоровье. 2021, 1 (1):56-64. DOI: 10.21045/2782-1676-2021-1-1-56-64.

Контактная информация: Тутельян Виктор Александрович, e-mail: tutelyan@ion.ru

Статья поступила в редакцию: 16.02.2021. Статья принята к печати: 04.03.2021. Дата публикации: 24.03.2021 бсуждая проблему общественного или популяционного здоровья, мы ведем речь, прежде всего, о том, что в его сохранении и поддержании ведущая роль принадлежит здоровому образу жизни, который складывается из многих составляющих. Это отсутствие вредных привычек, таких как избыточное потребление алкоголя, курение, качество окружающей среды, условия труда, научно обоснованный режим дня.

Однако главными из них являются здоровое питание и физическая активность. И если с физической активностью все более или менее понятно - это дозированные физические нагрузки, физкультура и спорт, то когда обсуждаем понятие здорового питания, мы сталкиваемся с большими трудностями как с согласованием понятийного аппарата, так и с объективным недостатком фундаментальных знаний об особенностях метаболизма и механизмах действия минорных компонентов пищи, в частности биологически активных веществ. Фактор питания наиболее значим, поскольку в обеспечение здоровья и работоспособности человека он вносит до 50\% от суммы всех учитываемых факторов (рис. 1). При этом нарушения питания составляют от 30 до $50 \%$ причин возникновения 
сердечно-сосудистых и онкологических заболеваний, сахарного диабета 2 типа, подагры, остеопороза и ожирения [1-3].

Так что же понимать под здоровым питанием? Здоровое питание - это, в первую очередь, безопасное питание. Пища может быть источником и носителем большого количества контаминантов как природного, так и антропогенного происхождения (рис. 2).

К контаминантам природного происхождения относятся бактерии и их токсины, микроскопические грибы и микотоксины, растения и фитотоксины, высшие грибы и их токсины, одноклеточные водоросли и фикотоксины, прионы, вирусы, простейшие, токсины животных. Контаминанты антропогенного происхождения - это тяжелые металлы, радионуклиды, пестициды, нитрозосоединения, остатки ветеринарных препаратов и др. Безусловно, это микроорганизмы, благоприятным субстратом для жизнедеятельности которых являются продовольственное сырье и пищевая продукция, такие как бактерии группы кишечных палочек, сальмонеллы, листерии, иерсении, энтеробактерии и др. Это те микроорганизмы, которые наиболее опасны и представляют реальную угрозу жизни человека $[4,5]$.
Конечно, это новые технологии, новые упаковочные материалы, применение которых требует очень серьезной и тщательной предварительной оценки безопасности и определения границ их опасности.

Это конгломерат тех потенциальных рисков, которые могут быть привнесены из внешней среды во внутреннюю среду человека и вызвать серьезные нарушения здоровья. Поэтому направление обеспечения безопасности пищи - это один из краеугольных камней, на которых зиждется здоровое питание.

Другая сторона вопроса. Пища - это источник энергии, пластического материала и целого ряда биологически активных веществ. Рацион здорового питания должен удовлетворять, по крайней мере, двум законам науки о питании.

Первый - это закон соответствия энергетической ценности рациона энерготратам организма, любое нарушение которого в ту или иную сторону приводит к потере здоровья, а в тяжелых случаях и при длительном нарушении - к смерти. Избыточное по калорийности питание приводит к формированию избыточной массы тела и ожирению возрастающей степени тяжести, рост которого в настоящее

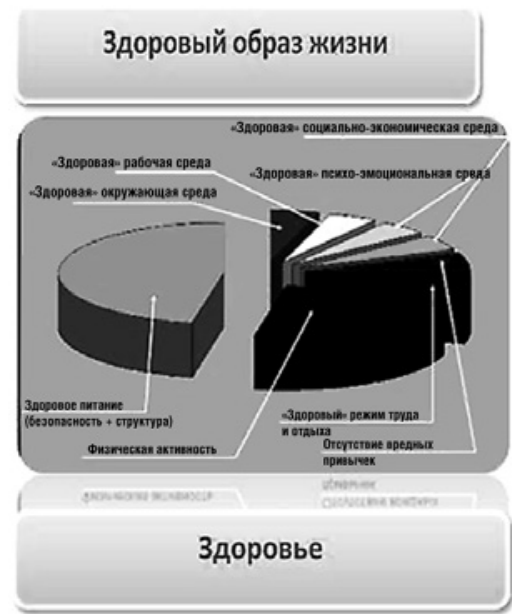

- Сердечно-сосудистые

- Ожирение

- Сахарный диабет

- Остеопороз

- Подагра

- Онкологические

Нарушения питания 30-50\% причин заболеваний

\section{ЗДОРОВОЕ ПИТАНИЕ может предотвратить 80\% инфарктов миокарда, инсультов и диабета}

Рис. 1. Структура питания, здоровый образ жизни и болезни 


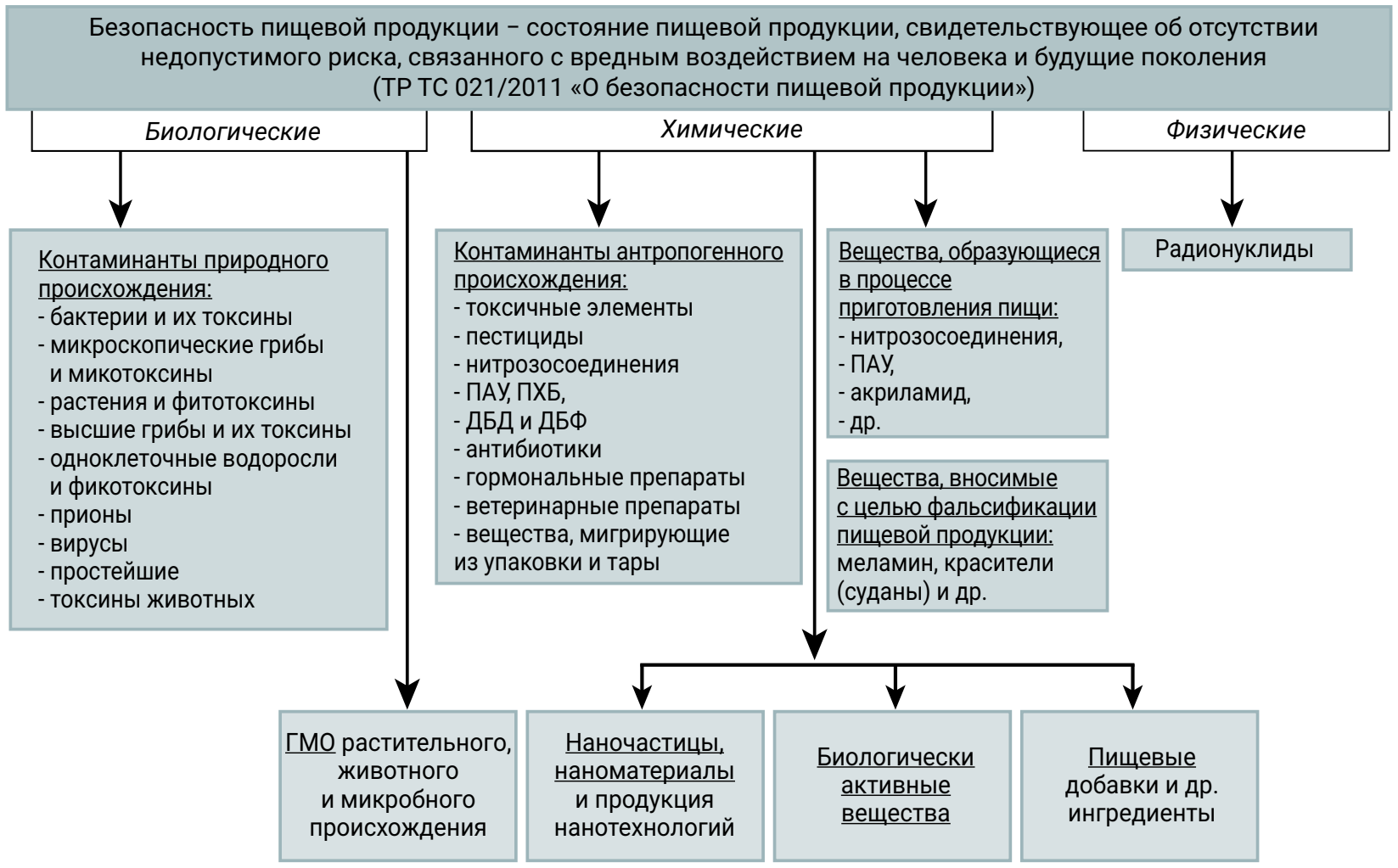

\section{Рис. 2. Показатели безопасности пищевой продукции}

время наблюдается у нас в России. При этом ожирение сопровождается развитием сопутствующих заболеваний: метаболического синдрома, сахарного диабета 2 типа, артериальной гипертензии, ишемической болезни сердца, атеросклероза, инсульта, инфаркта миокарда и многих других социально значимых неинфекционных заболеваний, представляющих серьезную угрозу для здоровья населения и занимающих ведущее место по вкладу в структуру смертности россиян $[6,7]$.

На этом фоне не теряют актуальности болезни, связанные с недостаточностью питания, выявляемой у 10-12\% населения, - это истощение, кахексия, связанные с различными заболеваниями, такими как нарушения работы ЖКТ или другими проблемами. Молодежь стремится отвечать требованиям моды и, ограничивая себя резко и неоправданно в пище или вовсе отказываясь от пищи, заболевает анорексией, последствия которой очень тяжелы и связаны с дальнейшими психическими нарушениями, требующими разностороннего воздействия. Тем не менее, такие состояния сейчас встречаются довольно часто, и выход из них представляет определенные трудности, требует от врачей высокой квалификации и участия в лечении не только диетологов, но и психиатров.

Но самое сложное - это соблюдение второго закона науки о питании - закона соответствия химического состава рациона нашим физиологическим потребностям в пищевых и биологически активных веществах, то есть В тех химических соединениях, которые нужны нам для того, чтобы быть здоровым и обеспечивать все необходимые жизненные функции. Это более 170 химических соединений, которые должны постоянно поступать в организм и, значит, постоянно присутствовать в нашей пище. Поэтому рацион здорового питания - это максимально разнообразный рацион, обеспечивающий поступление всех этих веществ. И понятия «вредный продукт», «полезный продукт» или «здоровый продукт» очень относительны, и я не позволяю себе 
использовать эти характеристики для отдельных продуктов. В целом рацион может быть здоровым или нездоровым. А отдельный продукт - это составная часть рациона. И здесь на первый план выходят количество и частота потребления тех или иных продуктов, которые могут оказывать негативное действие на здоровье или, наоборот, благоприятное. Поэтому рассуждая о здоровом питании, правильнее говорить о здоровом рационе, той структуре питания, которой должен придерживаться человек, максимально разнообразив свой рацион, включая в него продукты, являющиеся источниками всех необходимых пищевых и биологических активных веществ [8]. Каких?

Прежде всего, это белок, полноценный, включающий основные 20 аминокислот, или, по крайней мере, для взрослого человека 8 незаменимых, которые должны поступать с пищей обязательно. Для синтеза белка, работающего по принципу "все или ничего», присутствие всех аминокислот в аминокислотном пуле клетки, где осуществляется синтез белковых структур, является крайне необходимым, любое нарушение приводит к необратимым последствиям, а это не только снижение иммунореактивности и адаптационного потенциала, но и приостановление роста и развития. Поэтому белковая составляющая рациона была, есть и остается главной или генеральной линией обеспечения здорового питания.

Другой важнейший макронутриент - это жиры, и основное внимание здесь должно уделяться самым эссенциальным компонентам жирам, содержащим полиненасыщенные жирные кислоты, в особенности, семейства омега-3, которые необходимы для построения мембран клетки, и любое нарушение в их структуре приводит к нарушениям функций мембранных структур клетки, конформационным изменениям ферментов, встроенных в мембраны клеточных и субклеточных структур, изменениям их активности, приводящих к серьезным нарушениям метаболизма.

Определенные углеводные компоненты тоже являются эссенциальными, и необходи- мы для построения клеточных и субклеточных структур.

Конечно, к незаменимым факторам питания относятся витамины и минеральные вещества. Поскольку они являются частью активных центров ферментов, их недостаточность в составе рациона может привести к серьезным нарушениям метаболизма разнонаправленного характера. При анализе структуры питания населения России мы наблюдаем выраженный полигиповитаминоз (рис. 3). И в этом плане обеспеченность витаминами, минеральными веществами, микроэлементами в необходимых соотношениях и количествах является основой [9].

В последние годы особое внимание уделяется минорным компонентам пищи, обладающим биологической активностью. Это группа фенолов, полифенолов, индолов, изофлавонов и других соединений, присутствующих в достаточно большом количестве в растительной пище, прежде всего в плодах, овощах и фруктах, ограниченное поступление которых, может опять-таки привести к серьезным нарушениям метаболизма. Оказалось, что именно эти биологически активные соединения ответственны за экспрессию генов ферментов антиоксидантной защиты, ферментов метаболизма ксенобиотиков, которые обеспечивают нам здоровье. Пока до сих пор их эссенциальность полностью не доказана, но, по крайней мере, их необходимость показана, определены уровни их потребления, при которых они способны поддерживать здоровье и те уровни, при которых они опасны для нашего здоровья. Эти направления в науке бурно развиваются, и целью последних фундаментальных исследований является получение новых доказательств роли этих минорных соединений в процессах метаболизма и расшифровка механизмов их действия. Результаты последних исследований позволили, например, установить важную роль миоинозита в обмене углеводов и пуринов, синтезе фосфолипидов; карнитина и коэнзима Q10 - в энергетическом обмене; метилметионинсульфония - в реакциях биологического метилирования; индол-3-карбинола - в регу- 


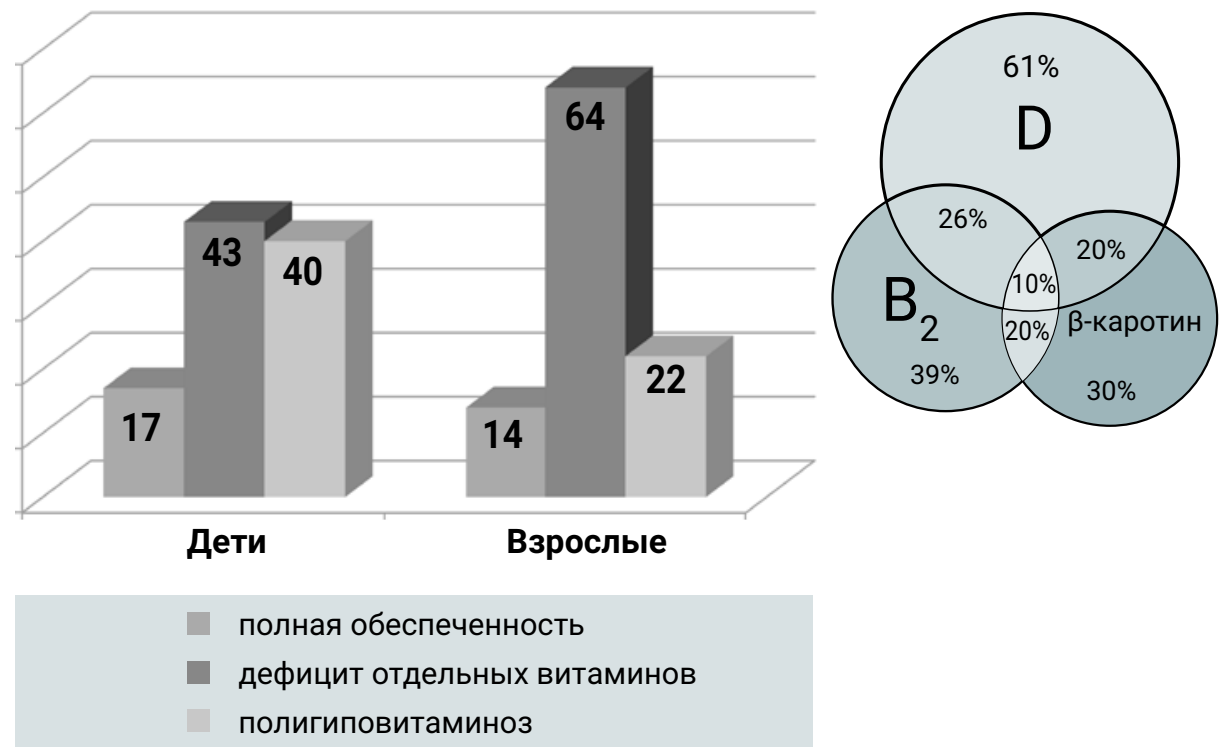

Рис. 3. Обеспеченность населения России витаминами, \%

ляции активности ферментов метаболизма ксенобиотиков; полифенолов - в регуляции защитно-адаптационного потенциала организма [8].

Итак, здоровое питание - это питание полноценное, находящееся в «юрисдикции» тех законов, которые я сформулировал раньше, и абсолютно безопасное.

Важнейшим компонентом реализации этих законов о питании является, конечно, образование населения. Понимание этих принципов и понятие здорового питания, расшифрованное и ретранслированное от результатов фундаментальных исследований к пониманию простым человеком этих незыблемых законов, крайне важно для обеспечения здоровья нации. И в этом плане здоровое питание это айсберг, основой которого, его подводной частью, невидимой невооруженным глазом, являются фундаментальные исследования, а вершиной - доведение этих фундаментальных знаний до понимания всеми людьми: и детьми, и взрослыми. Именно это позволит обеспечить общественное здоровье.

Я останавливался на медицинских проблемaх питания, но без наличия и доступности самих пищевых продуктов решить проблему, конечно, невозможно. Поэтому важнейший компонент здорового питания - интеграция медицинской науки с наукой и практикой аграрно-промышленного комплекса. Это те направления развития науки, которые способствуют не только увеличению количества продовольствия и обеспечения продовольственной безопасности страны, собственного производства (рис. 4).

Но это, конечно, помимо безопасности пищевой продукции, ее качество, оптимальное содержание полезных компонентов в продукте, повышение пищевой плотности продукта, чтобы с каждой частицей пищи мы получили максимальное количество необходимых пищевых и биологически активных веществ, источником которых является данный продукт.

Население развитых стран и население России стоит перед дилеммой. Технический прогресс принес людям великие блага, которые в корне изменили жизнь современного человека и практически освободили его от тяжелого труда. Это привело к резкому снижению энерготрат и, следовательно, существенному снижению объема необходимой пищи. Расчеты показывают, что в процессе формирования пищевых цепей потребности человека в микронутриентах могут быть удовлетворены за счет натуральных продуктов животного и растительного происхождения 
Физико-химические показатели

Функциональные свойства

Соответствие требованиям безопасности пищевой продукции

$>$ Подлинность заявленных в составе продукта ингредиентов

> Соответствие качества пищевого продукта требованиям нормативных документов

$>$ Соответствие заявленной энергетической и пищевой ценности

$>$ Соответствие заявленному физиологическому действию (для функциональных и специализированных продуктов)

Органолептические показатели

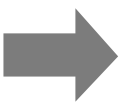

Соответствие вкуса, цвета, запаха, текстуры ожидаемым традиционным характеристикам

Рис. 4. Показатели качества пищевой продукции

при суммарной энергетической ценности рациона на уровне 3200-3500 ккал. в сутки. Однако к началу XXI столетия затраты энергии снизились до 2000 ккал. в сутки. При этом традиционный рацион, составленный из самых «свежайших» продуктов, дефицитен по витаминам на 20-30\%, а если учитывать потери эссенциальных нутриентов в процессе хранения, транспортировки, технологической и кулинарной обработки, то такой дефицит может достигать $50 \%$ суточной потребности.

Анализ структуры питания населения Российской Федерации свидетельствует о том, что мы достаточно далеки от соблюдения законов о питании. Как видно из представленных данных (рис. 5), мы потребляем существенно больше, чем нам необходимо, таких продуктов как хлебобулочные изделия, мясные продукты и колбасы с высоким содержанием жира и соли, и, конечно, сахар и кондитерские изделия, что ведет к увеличению калорийности рациона и несоответствию ее энерготратам. На этом фоне мы недополучаем овощи, фрукты, молочные продукты, богатые витаминами, микроэлементами, а также растительные масла, обеспечивающие нас эссенциальными ПНЖК.
Следствием такой структуры питания является рост распространенности избыточной массы тела и ожирения среди населения при одновременном дефиците жизненно важных микронутриентов и биологически активных соединений, что является причиной серьезного снижения адаптационного потенциала и устойчивости организма к неблагоприятным факторам окружающей среды.

В результате научно-технической революции человек сегодня оказался в жестокой конфронтации с природой. С одной стороны, образ жизни, физическая активность и питание людей в последние 100 лет существенно изменились, а потребности в микронутриентах остались практически неизменными. С другой стороны, природа как источник пищи осталась прежней, и угнаться за человеком ей не под силу. Природа не способна быстро менять то, что выстраивалось и развивалось тысячелетиями, а химический состав пищи человека, по существу, остался неизменным.

Мы все время стоим перед дилеммой есть меньше, чтобы быть здоровыми, но при этом есть больше, для того чтобы тоже быть здоровыми за счет поступления всех необходимых 


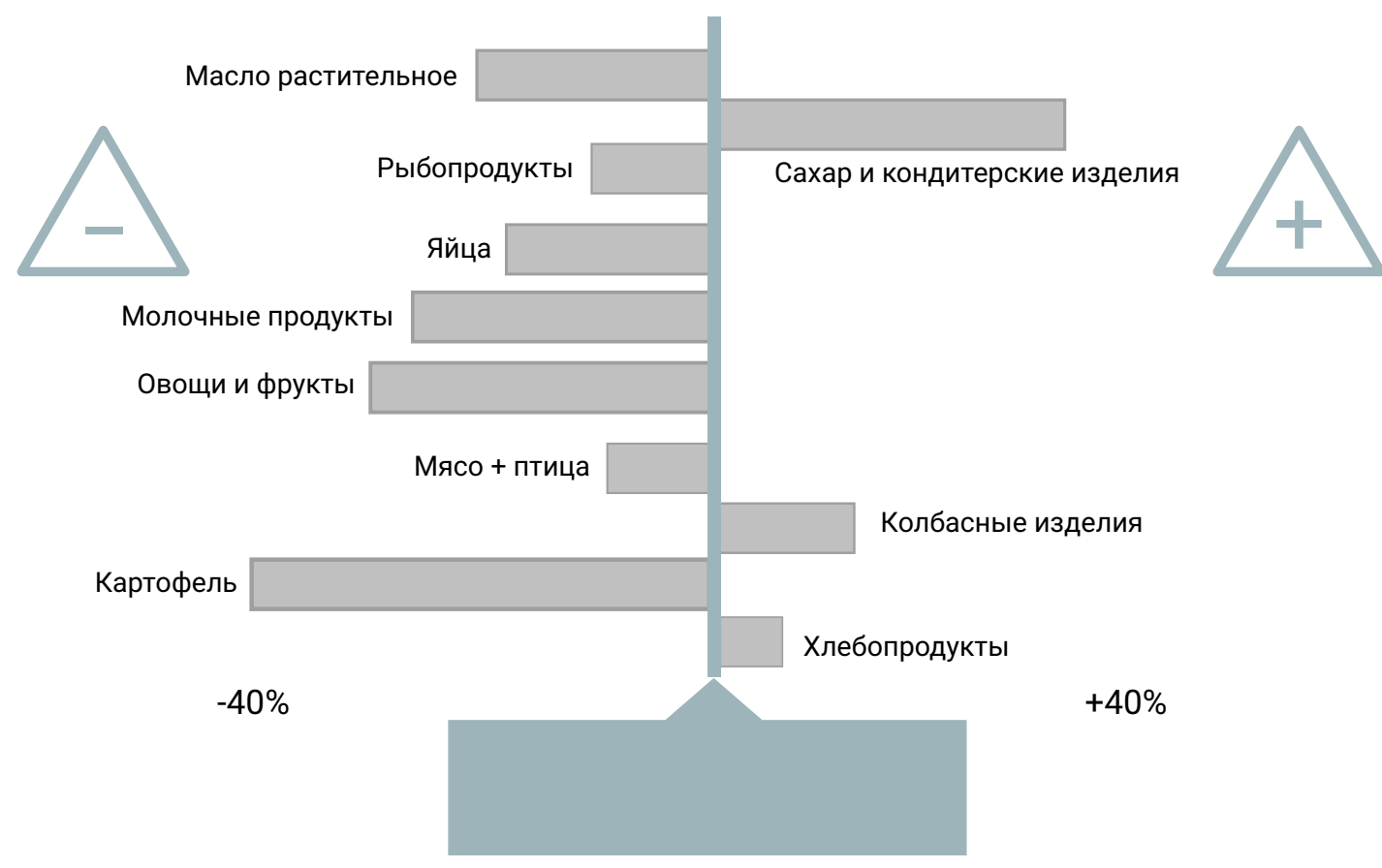

Рис. 5. Основные нарушения в структуре потребления пищевых продуктов в России, 2020 г.

компонентов пищи. Как же решить эту непростую проблему и найти баланс между полным удовлетворением потребностей человека в микронутриентах и обеспечением низкой калорийности рациона? Выход - это инновационные пищевые технологии, производство продукции, обогащенной незаменимыми факторами питания, специализированной пищевой продукции для диетического профилактического и лечебного питания, в которых снижено содержание компонентов, оказывающих неблагоприятное действие на здоровье и увеличено содержание тех, которые нам необходимы для того, чтобы сделать рацион компактным и обеспечивающим все наши потребности. Это можно и нужно сделать. И только так мы сможем обеспечить здоровье. Рацион здорового питания современного человека - это умелое сочетание традиционных натуральных продуктов, продуктов, полученных с использованием генно-инженерно-модифицированных организмов с улучшенным химическим составом (например, «золотой рис» с повышенным содержанием бета-каротина, соевые бобы, богатые незаменимыми полиненасыщенными жирными кислотами и др.), технологически модифицированным на стадии производства пищевой продукции за счет снижения содержания нежелательных пищевых веществ (например, соли, холестерина и др.) и повышения концентрации полезных ингредиентов - микронутриентов, биологически активных веществ и биологически активных добавок к пище, представляющих собой те же пищевые и биологически активные вещества, но «упакованные» в удобную и компактную форму в виде капсул, драже. Только так мы сможем обеспечить общественное здоровье.

Усилия, которые государство и Президент Российской Федерации направляют на реализацию Доктрины продовольственной безопасности Российской Федерации (Указ Президента Российской Федерации от 21.01.2020 № 20), Федерального закона от 02.01.2000 № 29-Ф3 «О качестве и безопасности пищевых продуктов» (ред. от 01.03.2020), Стратегии повышения качества и безопасности пищевой продукции Российской Федерации до 2030 года (Распоряжение Правительства Российской Федерации от 29.06.2016 № 1364-р), формируют государственную политику 
в области здорового питания населения, целью которой является снижение смертности и заболеваемости социально значимыми неинфекционными заболеваниями, обеспечение устойчивого естественного роста численности населения и повышение ожидаемой продолжительности жизни до 78-80 лет.

Чтобы достигнуть этих показателей и держать их на этом уровне (80+ лет) мы должны обеспечить доступное здоровое питание в течение всей жизни человека, начиная с момента ее зарождения (рис. 6). Мы должны преодолеть имеющиеся нарушения в структуре питания населения и обеспечить здоровый рацион всем и каждому.

Но усилий только государства для достижения этих целей недостаточно. Необходимы, в первую очередь, усилия каждого члена общества. Усилия, опирающиеся на знание и понимание основ здорового питания. И я бы на первое место поставил именно повышение уровня образованности населения в этой области человеческих знаний, ибо можно быть богатым и больным или даже умеренно бедным, но здоровым. И формируя общественное здоровье, наш журнал, первый выпуск которого вышел в свет, должен быть носителем этих передовых знаний и инновационных технологий здоровьесбережения.

\section{ЗАКЛЮЧЕНИЕ И ВЫВОДЫ}

В настоящей статье я попытался сформулировать те основополагающие принципы, реализуя которые можно достигнуть существенных успехов в обеспечении здоровья настоящего и будущих поколений.

1. Основным фактором, формирующим здоровье человека с момента зарождения жизни и до периода глубокой старости, является здоровый образ жизни, в первую очередь, здоровое питание и физическая активность.

2. Здоровое питание - это полностью безопасное питание, обеспечивающее физиологические потребности организма в энергии, пищевых и биологически активных веществах.

3. Анализ состояния фактического питания населения России выявил существенные отклонения от формулы оптимального питания, выражающиеся в избыточной калорийности рационов, избыточном потреблении жира, соли, сахара при одновременном недостаточном поступлении

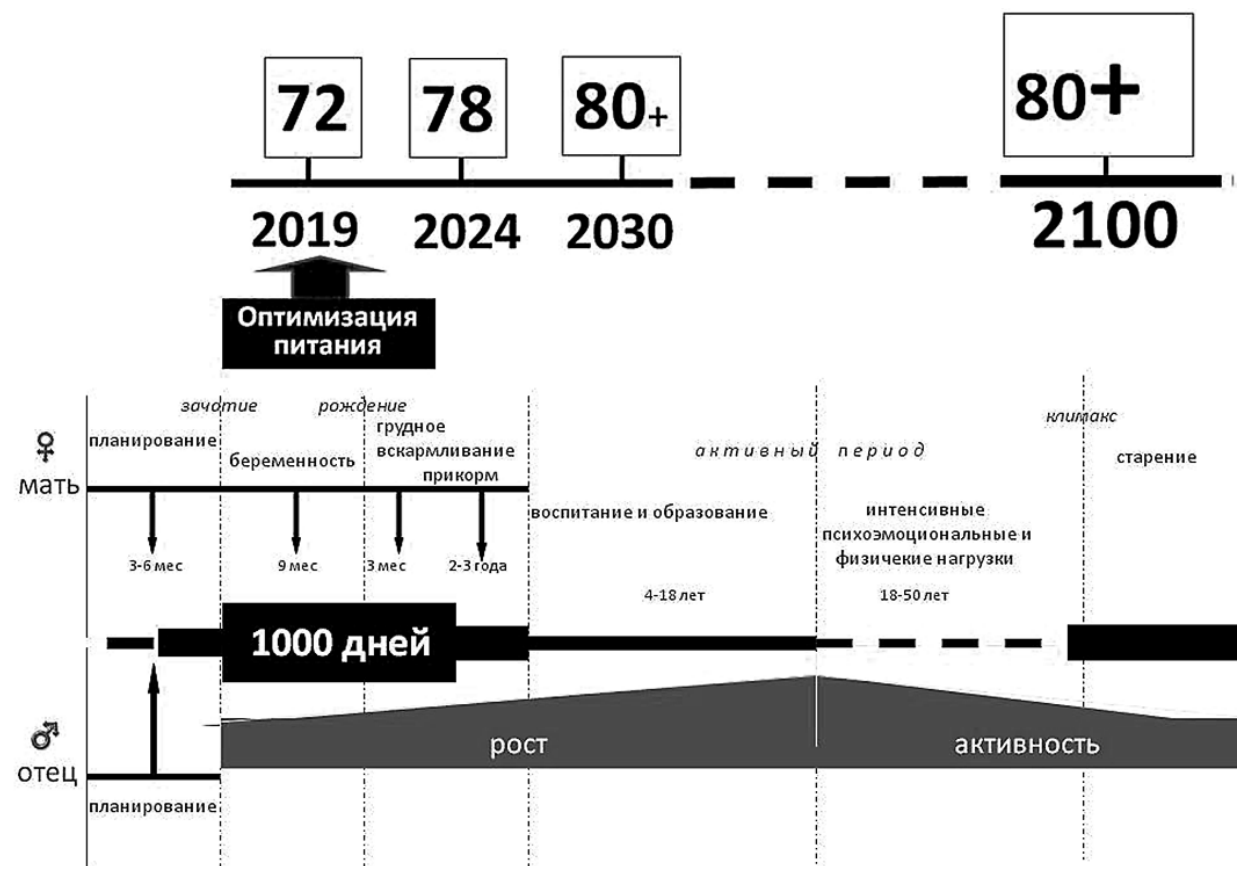

Рис. 6. Здоровое питание в течение жизни человека 
микронутриентов - витаминов, микроэлементов и биологически активных веществ.

4. Повышение уровня образованности всех слоев населения в вопросах здорового питания является важнейшим, наименее экономически обременительным и высокоэффективным инструментом здоровьесбережения нации.

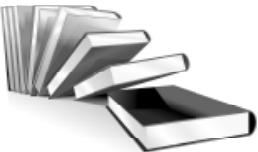

1. Глобальные факторы риска для здоровья. Смертность и бремя болезней, обусловленные некоторыми основными факторами риска. BO3, 2015. - 70 с. ISBN: 978-92-4-456387-8.

2. Качество жизни. Здоровье и питание: атлас / под ред. В.А. Тутельяна, Д.Б. Никитюка, Д.А. Буряка, С.Е. Акользиной, А.К. Батурина; пер. на англ. О.Н. Кишко. М.: Медицина, 2018. - 696 с. ISBN: 978-5-225-10039-1.

3. Тутельян В.А., Никитюк Д.Б., Шарафетдинов Х. Х. Здоровое питание - основа здорового образа жизни и профилактики хронических неинфекционных заболеваний // «Здоровье молодежи: новые вызовы и перспективы». Монография: в 5 т. / под ред. Н.Ф. Герасименко, П.В. Глыбочко, И. Э. Есауленко, В.И. Попова, В.И. Стародубова, В. А. Тутельяна. М.: Издательство «Научная книга», 2019. - Т. 3: Технологии снижения рисков здоровью. Профилактика и диспансеризация. Здоровое питание. С. 203-227. ISBN: 978-5-6043289-2-7.

4. Хотимченко С.А., Бессонов В.В., Гмошинский И.В., Кравченко Л.В., Седова И.Б., Шевелева С.А., Багрянцева О.В., Эллер К.И. Контаминанты // Нутрициология и клиническая диетология: национальное руководство / под ред. В.А. Тутельяна, Д.Б. Никитюка. - Москва: ГЭОТАР-Медиа, 2020. ISBN: 978-5-9704-5352-0.

5. Шевелева С.А., Черникова Е.А., Ефимочкина Н.Р. Биологическая безопасность// Нутрициология и клиническая диетология: национальное руководство / под ред. В.А. Тутельяна, Д.Б. Никитюка. - Москва: ГЭОТАР-Медиа, 2020. ISBN: 978-5-9704-5352-0.

6. Тутельян В.А. Оптимальное питание. Законы // Нутрициология и клиническая диетология: национальное руководство / под ред. В.А. Тутельяна, Д.Б. Никитюка. - Москва: ГЭОТАР-Медиа, 2020. - С. 22-25. ISBN: 978-5-9704-5352-0.

7. Шарафетдинов Х.Х., Плотникова О.А. Ожирение как глобальный вызов XXI века: лечебное питание, профилактика и терапия // Вопросы питания. - 2020. - Т. 89, № 4. - С. 161171. DOI: https://doi.org/10.24411/0042-8833-2020-10050.

8. Тутельян В.А., Никитюк Д. Б., Батурин А. К., Васильев А. В., Гаппаров М. М.Г., Жилинская Н. В., Жминченко В.М., Камбаров А. О., Коденцова В.М., Кравченко Л. В., Кулакова С. Н., Лашнева Н. В., Мазо В. К., Соколов А. И., Суханов Б. П., Хотимченко С. А. Нутриом как направление «главного удара»: определение физиологических потребностей в макро- и микронутриентах, минорных биологически активных веществах пищи // Вопросы питания. - 2020. T. 89, № 4. - C. 24-34. DOI: https://doi.org/10.24411/0042-8833-2020-10039.

9. Коденцова В.М., Бекетова Н. А., Никитюк Д. Б., Тутельян В. А. Характеристика обеспеченности витаминами взрослого населения Российской Федерации // Профилактическая медицина. - 2018. - Т. 21, № 4. - С. 32-37. DOI: https://doi.org/10.17116/profmed2018214322.

UDC: 614.2

Tutelyan V.A. Healthy food for public health (Federal Research Center for Nutrition, Biotechnology and Food Safety, Moscow, Russia; I.M. Sechenov First Moscow State Medical University, Moscow, Russia)

Abstract: The concept of healthy nutrition as a key factor shaping human health in all periods of life, as well as its fundamental principles based on the basic laws on nutrition, is considered. Special attention is paid to the issues of food safety, ensuring the physiological needs for energy, food and biologically active substances, the importance of diversity and balance of the diet. The main violations of the nutrition structure of the population of the Russian Federation are reflected and effective tools for its improvement, prevention of alimentary-dependent non-communicable diseases and health-saving of the nation are proposed.

Keywords: public health, healthy food, minor components of food, metabolism, biologically active substances, food safety.

For citation: Tutelyan V.A. Healthy food for public health // Public health. 2021; 1(1): 56-64. DOI: 10.21045/2782-16762021-1-1-56-64 